\title{
Sexuality in Patient with Breast Cancer Hospitalized in Professional Nursing Vision
}

\author{
Lilian Organista* \\ Rio de Janeiro Nursing University, Brazil \\ *Correspondence to: DLilian Organista, Rio de Janeiro Nursing University, Brazil
}

Received: October 05, 2017; Accepted: October 17, 2017; Published: October 27, 2017;

\begin{abstract}
The study seeks to investigate aspects of sexuality of women with breast cancer admitted. The emergence of the study took place at the time of my professional practice where I came across patient dialogues, and health professionals with the behavior of women in different times, having sexual practice and professional assistants, on the other hand the kind of suppressed such an attitude as well as the patients more "brawling". I realized the need to discuss such issues: women who are hospitalized for treatment that theoretically move with biopsicoemocional, self-image and self-esteem, should have "head for such behavior? There is a need of nurses to direct a group for care to sexuality. Aiming to analyze the psychophysical need, using the philosophical approach of Jean Watson. Methodology the study presents a review and synthesis of the literature on the theory of nursing sexual need. Final considerations the nurse has the key role of facilitating communication of sexuality, not to become fragmented, to emphasize the importance of the role of the sexual partner. Thus discussion related to sexual health.
\end{abstract}

\section{Introducion}

The study seeks to investigate aspects of sexuality of women with breast cancer interned. The emergence of the study took place at the time of my professional practice where I came across patient dialogues, and health professionals with the behavior of women in different times, having sexual practice and professional assistants, on the other hand the kind of suppressed such an attitude as well as the patients more "excited".

In the context of health, the educational process consists much more than the simple act of teaching. The client, who is often mistakenly called a passive individual, is a key player in the care process, since we already know that the process of health care is dynamic and requires the participation of both parties, whether caregiver or individual who will receive the care.

\section{Justification}

I realized the need to discuss such issues: women who is hospitalized for treatment that theoretically move with biopsicoemocional, selfimage and self-esteem,should have "head for such behavior? There is a need of nurses to direct a group for care to sexuality.

By identifying the knowledge of the caregivers, we can analyze the quality of the orientation group, in which the study may contribute to the educational interventions to be proposed to this group, with the aim of improving the caregiver's vision to young patients with cancer breastfeeding, thus favoring better qualified care.

\section{Methodology}

Aiming to analyze the psychophysical need, using the philosophical approach of Jean Watson.
Methodology the study presents a review and synthesis of the literature on the theory of nursing sexual need.(possible adaptation) [Figure 1]

\section{Objective}

\section{General objective}

To analyze the process of health education in the approach of the group of guidance by the nurse in hospitalized patients with breast cancer in the perception of the caregiver.

\section{Specific Objectives}

To identify the communication between the nurse practitioner and the patient with the partner.

\section{Final Consideration}

The nurse has the key role of facilitating communication of sexuality, not to become fragmented, to emphasize the importance of the role of the sexual partner. Thus discussion related to sexual health, through the guidance group.

\section{References}

1. Ahmad EC, Coler MS, Nóbrega MML (2005) Jean Watson's nursing theoryfocused on human sexuality. Braz J Nurs

2. SMA, Panobianco MS, Ferreira Gozzo TO, Abdulla AM (2013) Sexualityof women with breast cancer: analysisof nursing science. Florianópolis: text Context Nurses 30: 835-42

3. National Cancer Institute (2013) Actions directed to improved appearance of patients have strong impact on the quality of the treatment-Self-esteem is fundamental. Rev Cancer Network 24-27

4. Junqueira LCU, Vieira Giami, Saints in MA (2013) Analysis of communication about sexuality, established by nurses, with patients in the health care context of breast cancer. Interface 17: 89-101 


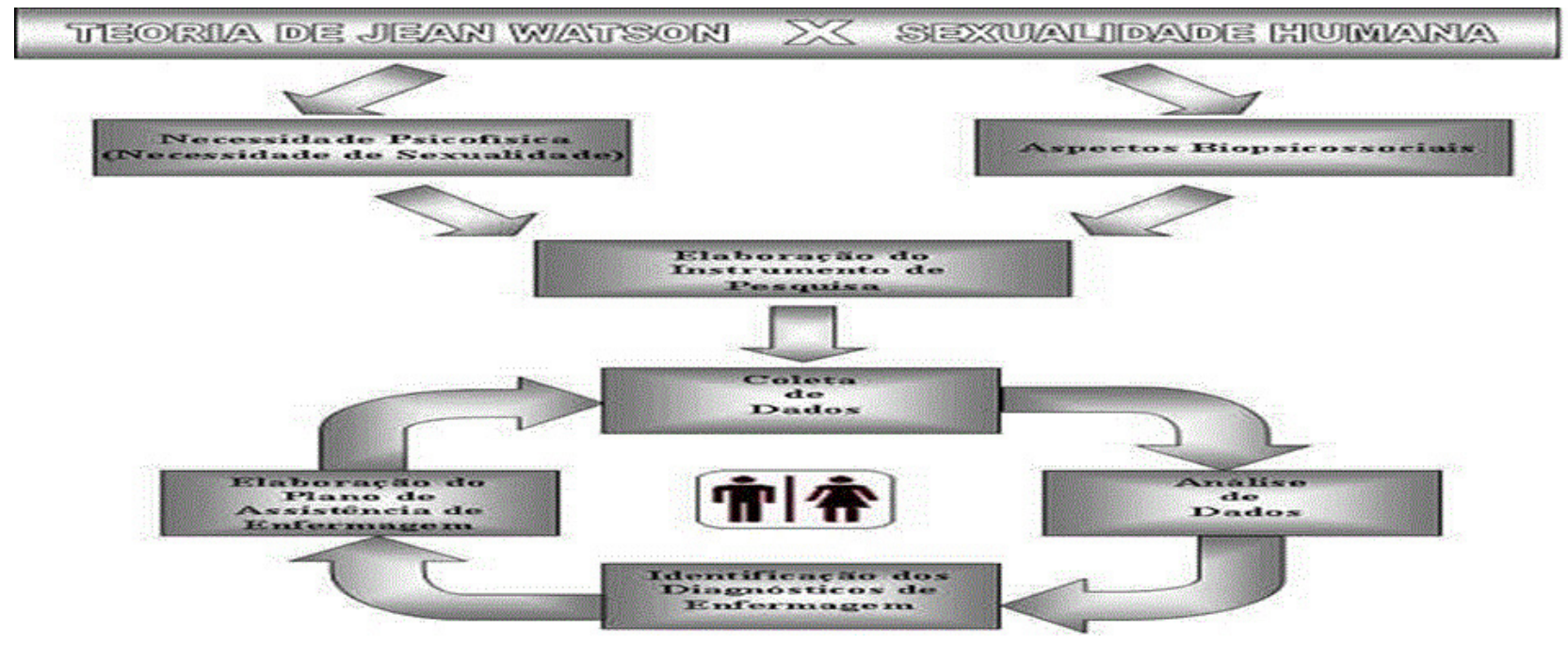

Figure 1. 